\title{
SISTEM INFORMASI REKAM MEDIS PASIEN DI BIDAN EVI BERBASIS JAVA
}

\author{
Muhamad Tofan ${ }^{1}$, Mercy Hermawati ${ }^{2}$, Rahmawati Yuliani ${ }^{3}$ \\ Program Studi Teknik Informatika, Fakultas Teknik dan Ilmu Komputer, \\ Universitas Indraprasta PGRI \\ Jalan Raya Tengah No 80, Kelurahan Gedong, Pasar Rebo, Jakarta Timur \\ muhamad.tofan.28@gmail.com ${ }^{1}$, mercy.hermawati@gmail.com ${ }^{2}$, rhmwtyuliani@gmail.com ${ }^{3}$
}

\begin{abstract}
Abstrak
Teknologi dapat membuat pekerjaan menjadi lebih efisien, pendataan rekam medis disebuah tempat praktek kebidanan membutuhkan manajemen yang baik pada umumnya yang dilakukan oleh perawat di Bidan Evi. Pengolahan data rekam medis masih menggunakan cara manual yang menyebabkan lambatnya pengolahan data yang tidak terstruktur dengan baik. Mengatasi permasalahan kelambatan dan akurasi data maka dilakukan perancangan sistem informasi pengelolaan data rekam medis menggunakan bahasa pemrograman java dan database MySql. Pembuatan perangkat lunak bertujuan untuk memudahkan proses sistem pendataan menjadi terkomputerisasi. Metode penelitian yang digunakan adalah metode kualitatif yang menyajikan data berupa teks dan metode pengembangan sistem waterfall. Hasil dari penelitian diharapkan menjadi lebih mudah dalam proses pendapataan. Sistem yang ada pada aplikasi rekam medis menjadi terkomputerisasi, rapih dalam hal penyimpanan data dan laporan menjadi efektif.
\end{abstract}

Kata Kunci: Rekam Medis, MySql, Sistem Informasi.

\begin{abstract}
Data collection of medical records in a place of midwifery practice necessitates good management in general, which is conducted out by nurses in bidan Evi. Medical record data processing is still done by hand, which results in sluggish processing of unstructured data. The design of medical record data management information systems employing java programming language and MySql database to overcome the problem of data slowness and correctness. The goal of software development is to make the process of computerizing data collection methods easier. The research approach employed is a qualitative method that uses text to provide data and waterfall system development methods to construct the system. The study's findings are likely to make the decision-making process easier. In medical record applications, the existing system becomes digitized, neat in terms of data storage, and reports become effective.
\end{abstract}

Keywords: Medical Records, MySql, Information Systems.

\section{PENDAHULUAN}

Rekam Medis adalah keterangan baik yang tertulis maupun yang terekam tentang identitas, anamnesa, penentuan fisik laboratorium, diagnosa segala pelayanan, dan tindakan medis yang diberikan kepada pasien, dan pengobatan baik yang dirawat inap, rawat jalan, maupun yang mendapatkan pelayanan darurat (Yanmed, 2012). Biasanya pada proses pengolahan data yang masih manual membutuhkan waktu yang lama, hasil yang kurang akurat sehingga terjadinya pengolahan data yang kurang efisien, tetapi berbeda dengan sistem pengolahan data yang sudah menggunakan komputer, proses pengolahan data yang menjadi cepat dan informasi lebih yang dihasilkan akan lebih akurat. Tujuan penelitian pada artikel ini untuk memudahkan proses sistem pendataan yang masih manual menjadi terkomputerisasi serta dibuatnya tampilan interface yang mudah untuk digunakan oleh setiap perawat yang ada di Bidan Evi. Hasil observasi yang dilakukan dari permasalahan yang ada di Bidan Evi peneliti membuat sistem informasi yang meliputi data rekam medis yang tersimpan ke dalam database dan pembuatan laporan yang tersistem agar menjadikan aplikasi tersebut sebagai sistem informasi, adapaun pengertian sistem informasi yaitu suatu sistem yang menyediakan informasi untuk manajemen dalam mengambil keputusan dan juga untuk menjalankan operasional perusahaan, di mana sistem tersebut merupakan kombinasi dari orang-orang, teknologi informasi dan prosedur-prosedur yang tergorganisasi (Dimas, 2013). 


\section{PENELITIAN RELEVAN}

Beberapa penelitian yang relevan dengan penelitian ini adalah :

Penelitian oleh Muhamad Soleh, Universitas Esa Unggul Jakarta, dengan judul penelitian Desain Iteraksi Aplikasi Rekam Medis Berbasis UCD. Tujuan penelitiannya yaitu membuat sistem rekam medis berbasis Java J2SE, membuat sistem rekam medis yang belum terkomputerisasi sehingga menjadi terkomputerisasi, dan membuat sistem rekam medis yang terintegrasi dengan baik(Soleh, Ii,\&Joko, 2014). Penelitian selanjutnya oleh Aditya Pamungkas, Universitas Pamulang Tangerang, dengan judul penelitian Rancangan Bangun Sistem Informasi Pelayanan Kesehatan Untuk Rekam Medis Rawat Jalan Pada Klinik Pratama Afiyah Medika Berbasis Desktop. Tujuan penelitiannya yaitu mengusulkan sistem informasi untuk mempermudah dalam pengolahan data pasien dan rekam medis (Pamungkas, 2020).

\section{METODE PENELITIAN}

Metode penelitian adalah suatu cabang ilmu pengetahuan yang membicarakan/mempersoalkan mengenai cara-cara melaksanakan penelitian sampai menyusun laporannya) berdasarkan faktafakta atau gejala-gejala secara ilmiah (Achmadi, 2011). Metode penelitian yang digunakan adalah metode grounded (Grounded Research) yaitu suatu metode penelitian berdasarkan pada fakta dan menggunakan analisis perbandingan dengan tujuan mengadakan generalisasi empiris, menetapkan konsep, membuktikan teori, mengembangkan teori, pengumpulan dan analisis data dalam waktu yang bersamaan serta metode pengembangan sistem waterfall. Pengertian waterfall sendiri antara lain yaitu adalah aplikasi penerapan dari penemuan permasalahan (problem solving) yang didapat dari pendekatan sistem (system approach) menjadi pengembangan dari solusi sistem informasi terhadap masalah bisnis (Rosa \& Shalahuddin, 2018). Tempat penelitian ini dilakukan pada Bidan Evi yang beralamat di jalan cilayu Rt 04 Rw 03 No 65 Kelurahan Cisalak Pasar Kecamatan Cimanggis Kota Depok. Metode pengumpulan data yang peneliti lakukan adalah metode studi kepustakaan yaitu mengumpulkan data yang diperoleh dari berbagai sumber buku di perpustakaan serta sumber-sumber lain sebagai penunjang dalam menyelesaikan penelitian ini, observasi yaitu peninjauan langsung ke tempat Bidan Evi yang dilakukan selama 2 minggu untuk mengamati kegiatan yang dilakukan oleh para perawat yang berkaitan dengan bidang yang akan dibuat peneliti, dan wawancara yaitu dilakukan untuk mencari data dan informasi tentang hal-hal yang dibutuhkan dalam penelitian.

\section{Tahapan-Tahapan Metode Pengembangan Sistem Waterfall}

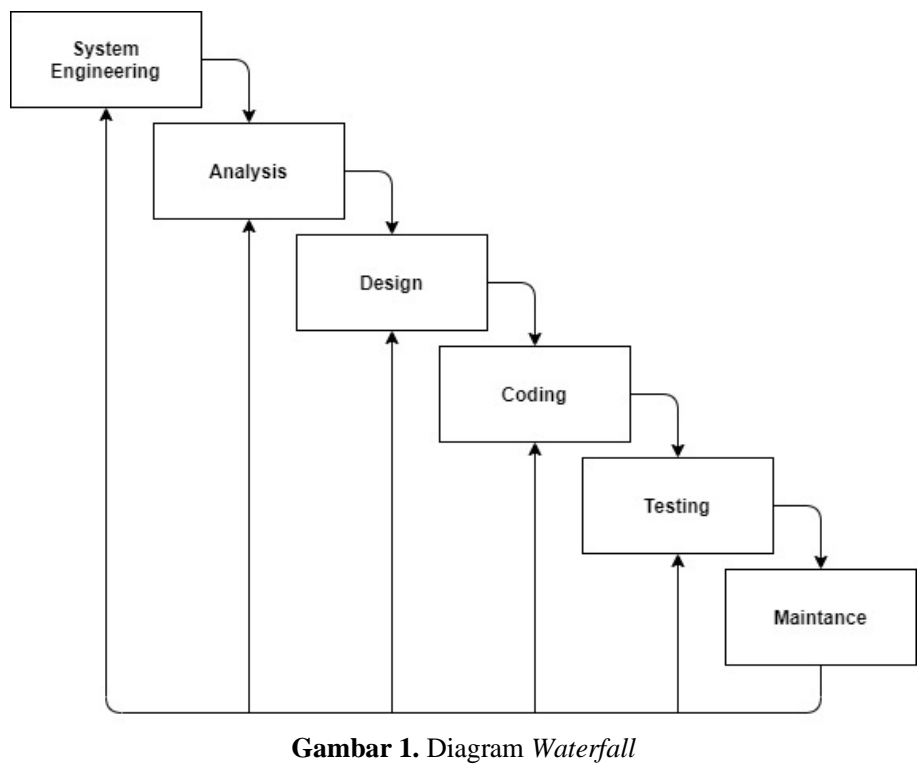


1. System Engineering

Dalam tahap ini peneliti melakukan pengumpulan kebutuhan seluruh elemen sistem seperti data-data yang digunakan. Dimana elemen-elemen tersebut dapat menunjang dalam pengembangan sistem informasi rekam medis.

2. Analysis

Analisis adalah suatu usaha untuk mengurai suatu masalah atau fokus kajian menjadi bagianbagian (decomposition) sehingga susunan/tatanan bentuk sesuatu yang diurai itu tampak dengan jelas dan karenanya bisa secara lebih terang ditangkap maknanya atau lebih jernih dimengerti duduk perkaranya (Kasmir, 2019). Pada tahap menganalis kebutuhan sistem dilakukan pengumpulan kebutuhan dengan berfokus pada perangkat lunak, meliputi informasi, fungsi masing-masing pada bagian sistem, kerja atau cara kerja dan antar muka. Lalu menyediakan perangkat dan teknik yang dapat membantu peneliti untuk menentukan kebutuhan melalui sistem yang dapat membantu peneliti untuk menentukan kebutuhan melalui sistem yang telah berjalan pada sistem informasi persediaan dalam melakukan pengolahan data-datanya. Perangkat yang dimaksud adalah penggunaan Unifid Modeling Language (UML) untuk menyusun daftar input, proses, output fungsi bisnis.

3. Design

Pada tahap ini dilaksanakan perancangan struktur data, struktur perangkat lunak, rincian prosedur dan karakteristik antar muka. Serta dirancang pula tampilan layar seperti form masukan dan form keluaran dari sistem yang akan dirancang.

4. Coding

Pada tahap ini dibuat coding sistem informasi rekam medis yang merupakan tahap untuk membuat suatu kode tentang aplikasi yang akan dibuat agar dibaca dan diterjemahkan oleh komputer.

5. Testing

Sebelum aplikasi rekam medis dapat digunakan dengan baik, harus dilakukan pengujian terlebih dahulu. Rangkaian pengujian ini dijalankan bersama-sama dengan data aktual dari sistem yang sudah ada atau dari sistem yang sedang berjalan.

6. Maintance

Bagian akhir dari siklus pengembangan sistem laporan produksi dan tahap ini dilakukan setelah perangkat lunak dipergunakan, berupa kegiatan correntive maintance, yaitu mengoreksi kesalahan pada perangkat lunak, yang baru diketahui pada saat perangkat lunak dipergunakan. Dengan ada correntive maintance terhadap sistem laporan hasil produksi maka kesalahankesalahan yang terdapat di aplikasi ini dapat diperbaiki.

\section{HASIL DAN PEMBAHASAN}

Alternatif Penyelesaian Masalah

Beberapa uraian masalah yang dihadapi dalam sistem pemrosesan data, transaksi pembayaran dan pembuatan laporan, maka peneliti memberi alternative penyelesaian masalahnya, yaitu:

1. Aplikasi sistem informasi rekam medis yang terkomputerisasi sehingga dapat dihasilkan informasi yang lebih cepat dan tepat.

2. Perancangan database untuk sistem pengolahan data rekam medis sehingga penyimpanan data mudah untuk diolah kembali.

3. Proses transaksi pembayaran menjadi terkomputerisasi dan tersimpan dalam database.

4. Membuat aplikasi yang dapat mudah dipahami oleh setiap user agar dapat digunakan oleh setiap user, baik yang memahami dalam pengoperasian komputer maupun tidak.

\section{Usecase Diagram}

Usecase adalah deskripsi fungsi dari sebuah system dari perspektif pengguna. Usecase bekerja dengan cara mendeskripsikan tipikal interaksiantar User (pengguna) sebuah system dengan sistemnya sendiri melalui sebuah cerita bagaimana sebuah sistem dipakai (Windu \& Gata, 2013). 


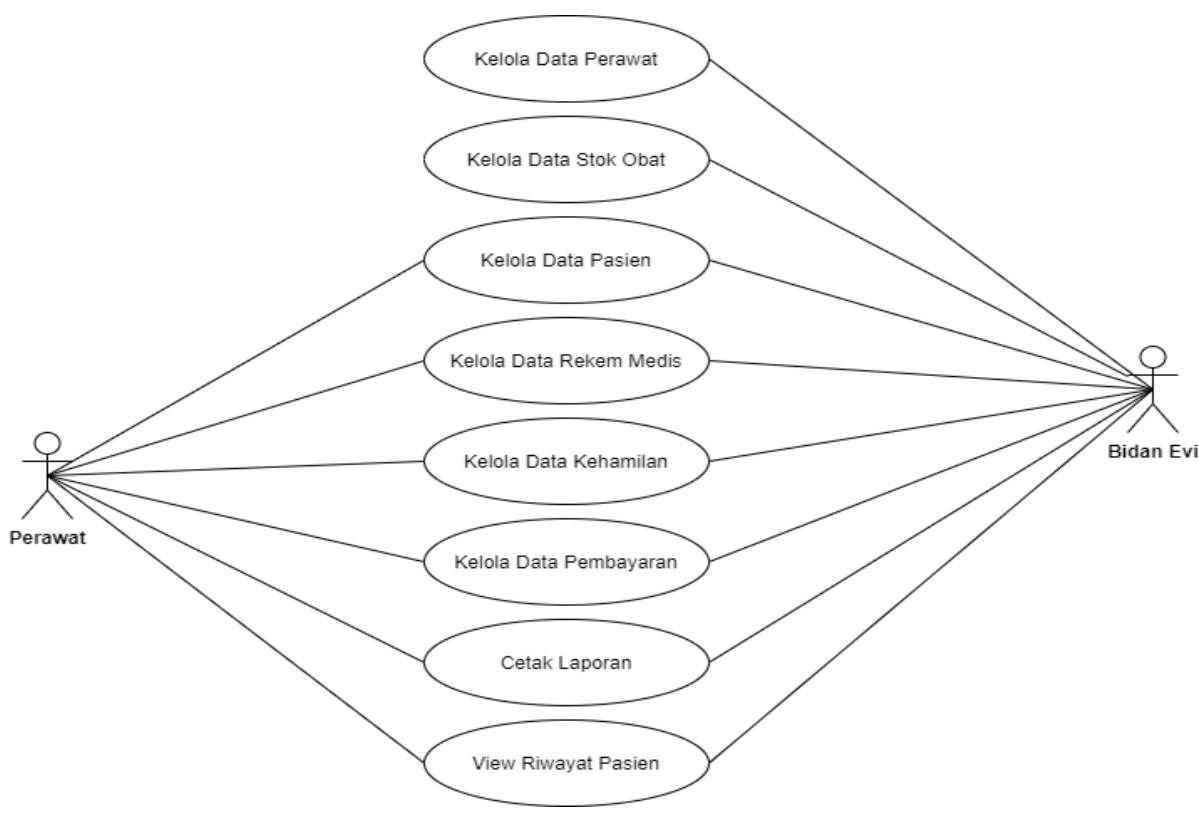

Gambar 2. Usecase Diagram

\section{Class Diagram}

Class diagram menggambarkan struktur sistem dari segi pendefinisian kelas-kelas yang akan dibuat untuk membangun sistem. Kelas memiliki apa yang disebut atribut dan method atau operasi(Rosa AS, 2014).

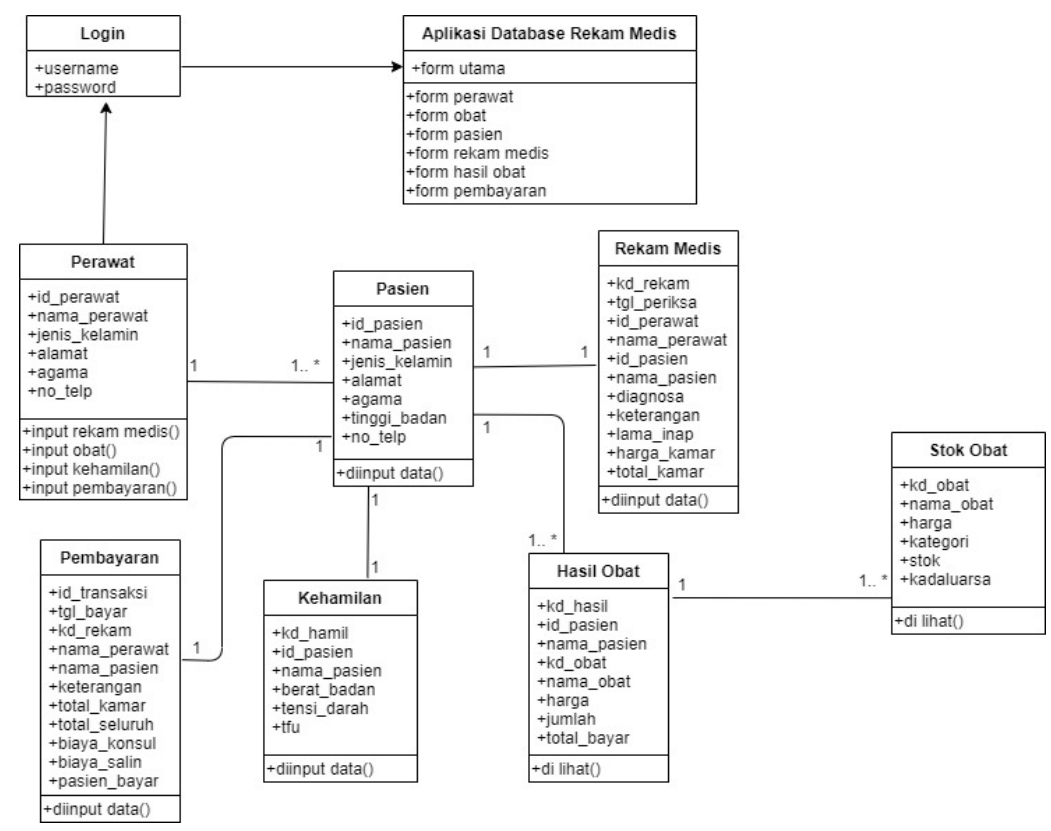

Gambar 3. Class Diagram

\section{Entity Relationship Diagram (ERD)}

ERD (Entity Relationship Diagram) merupakan tools yang digunakan untuk memodelkan struktur data dengan menggambarkan entitas dan hubungan antara entitas (relationship) secara abstrak (Mulyani, 2014). 


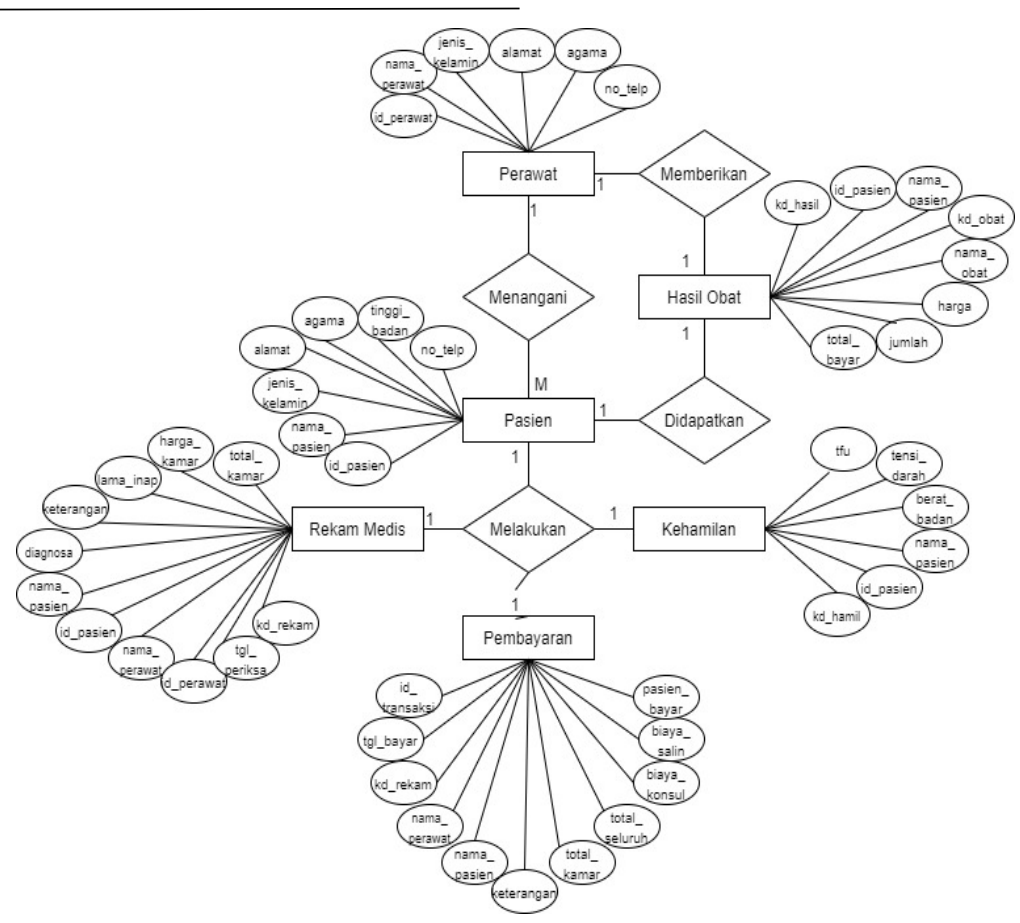

Gambar 4. Entity Relationship Diagram (ERD)

\section{Tampilan Layar}

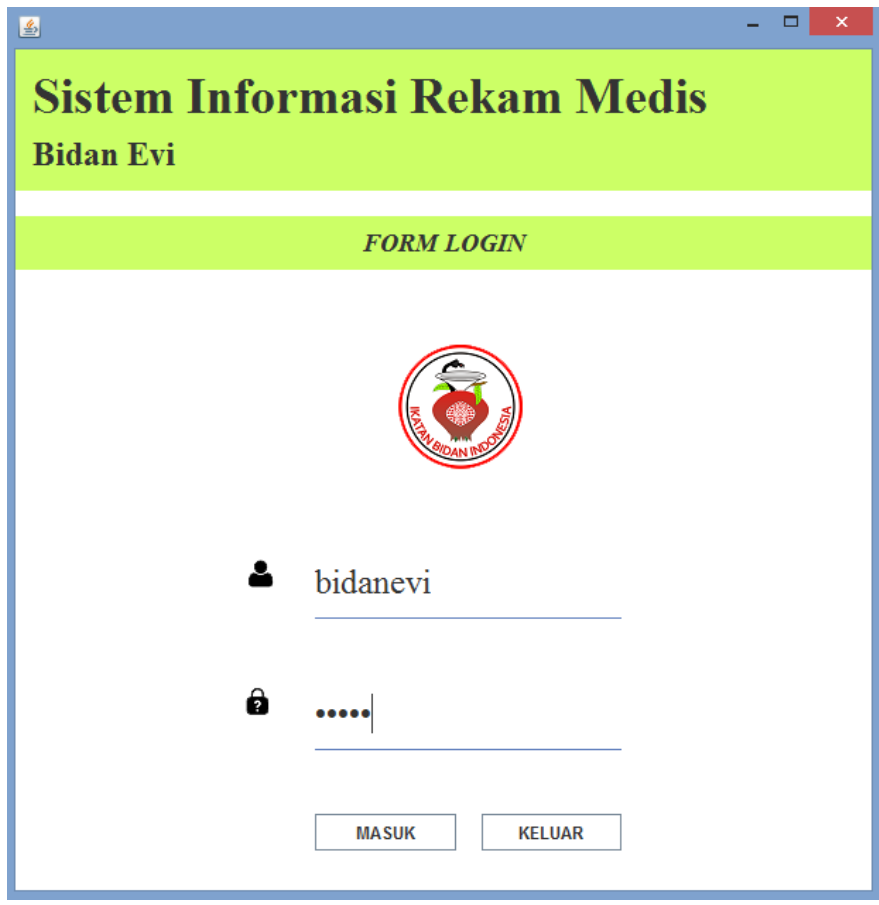

Gambar 5. Menu Login

Tampilan login yaitu menu yang pertama kali akan muncul ketika user menjalankan aplikasi, dan ketika user berhasil login maka akan masuk ke form selanjutnya yaitu form halaman utama 


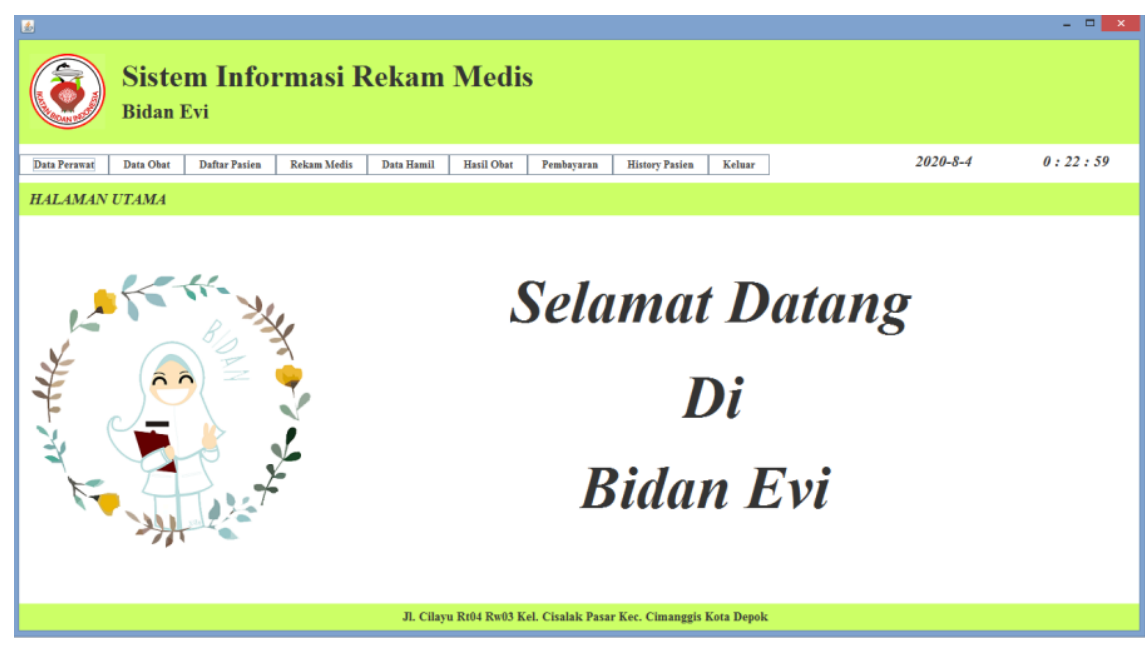

Gambar 6. Halaman Utama

Pada tampilan halaman utama adalah dasar program aplikasi rekam medis sebagai penunjang untuk mengakses menu-menu yang lainnya. Pada halaman menu utama terdapat menu perawat, menu pasien, menu obat, menu rekam medis, menu kehamilan, menu hasil obat, menu pembayaran, menu riwayat pasien dan menu keluar.

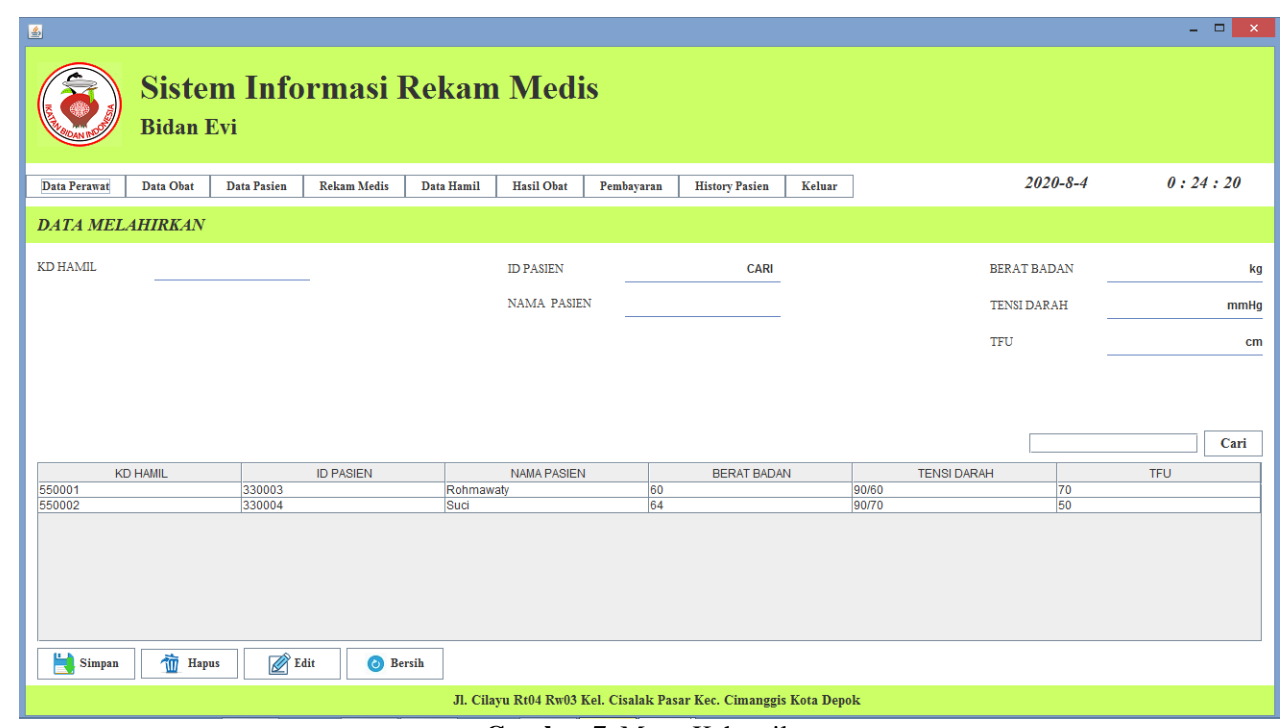

Gambar 7. Menu Kehamilan

Tampilan menu kehamilan dilakukan pada saat pasien melakukan pemeriksaan pada Bidan Evi, ketika data disimpan maka akan masuk ke dalam database dan data dapat diubah, dihapus, serta dibersihkan. 


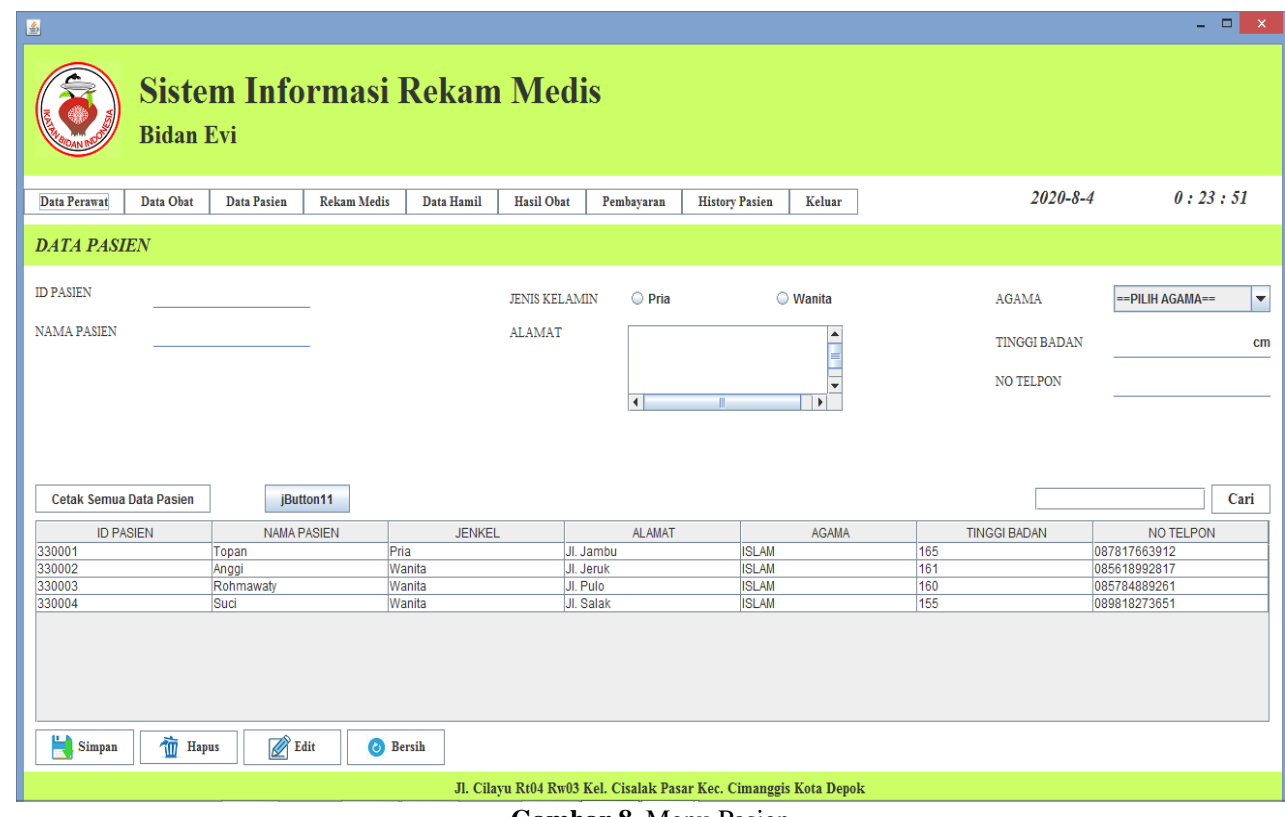

Gambar 8. Menu Pasien

Tampilan menu pasien dilakukan pada saat pasien melakukan pendaftaran pada Bidan Evi, ketika data disimpan maka akan masuk ke dalam database dan data dapat diubah, dihapus, serta dibersihkan.

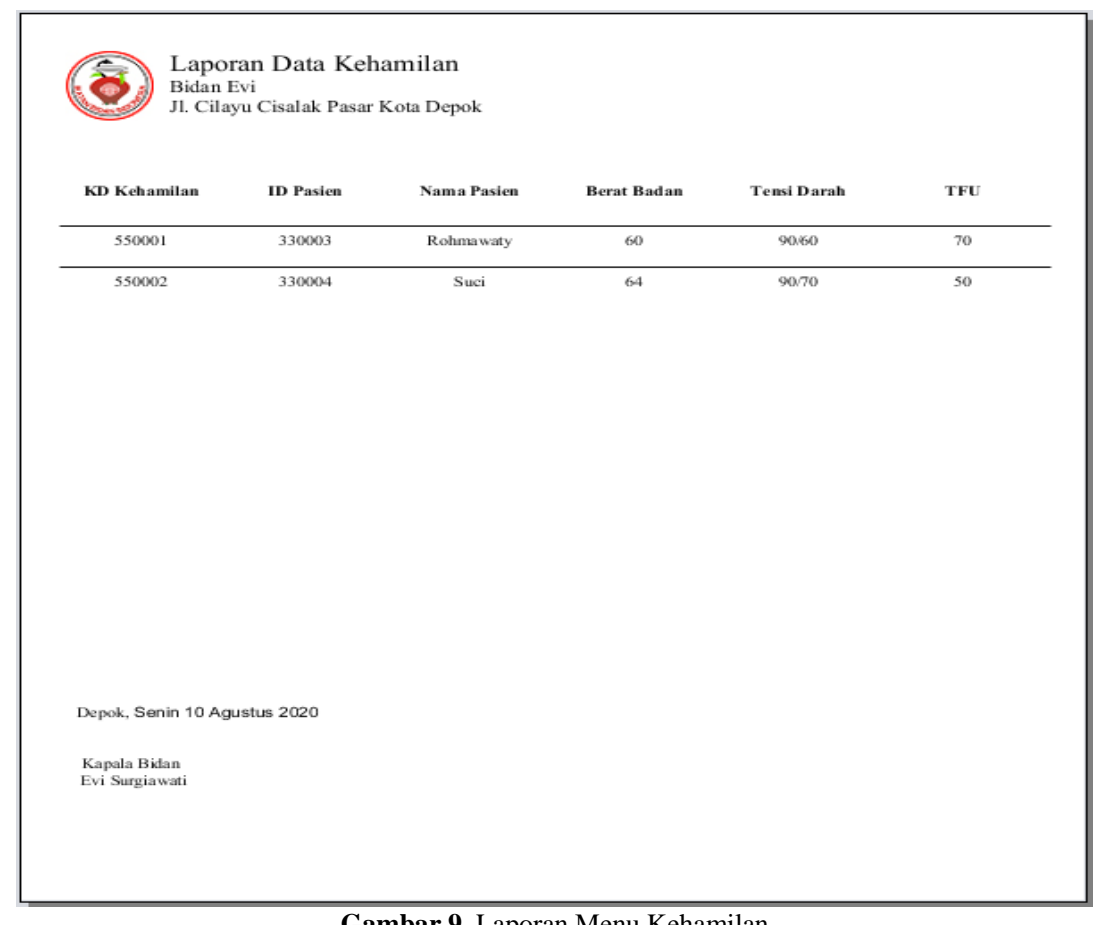

Tampilan laporan menu kehamilan merupakan hasil dari inputan data kehamilan, kemudian data tersebut dicetak lalu menghasilkan keluaran berupa laporan data kehamilan untuk diserahkan kepada kepala bidan. 


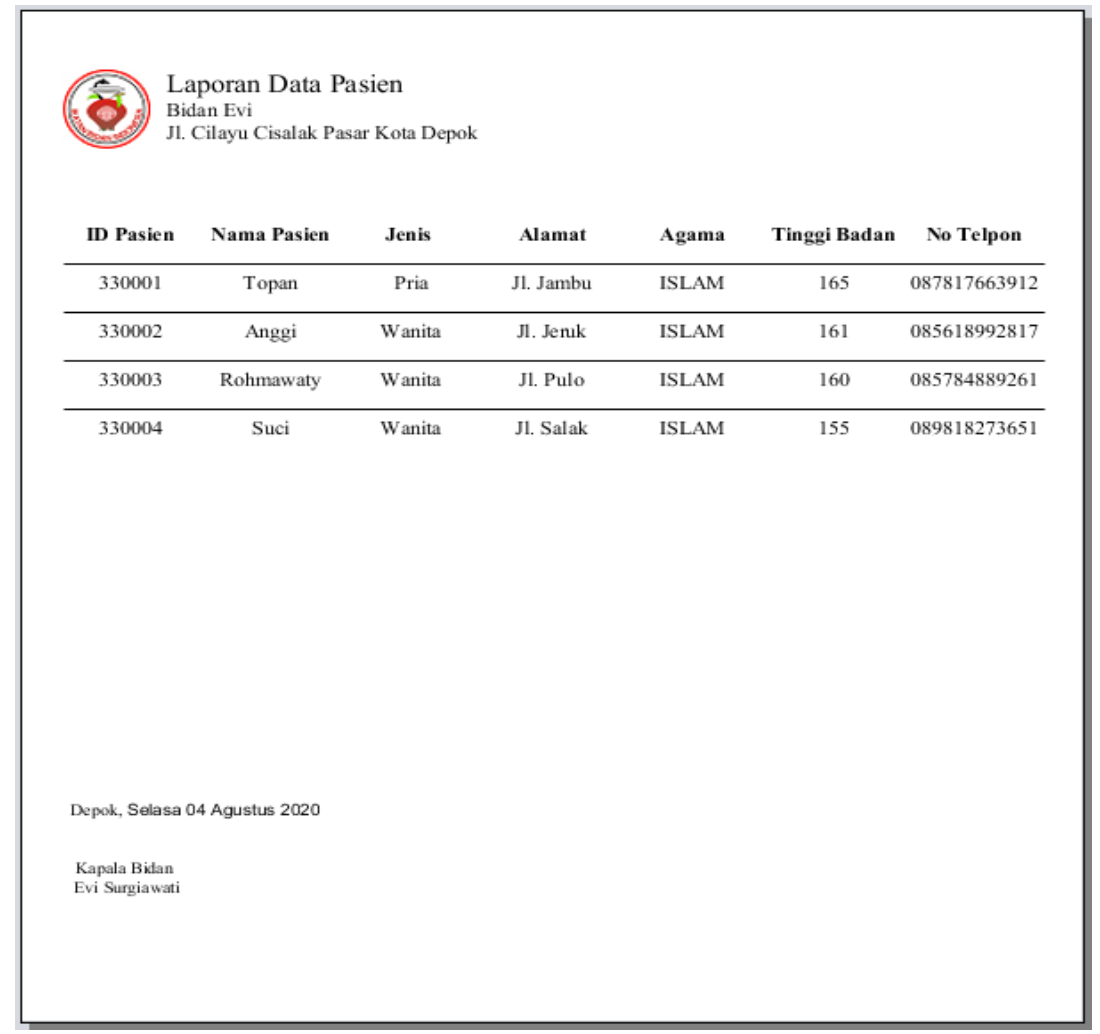

Gambar 9. Laporan Menu Pasien

Tampilan laporan menu pasien merupakan hasil dari inputan pasien, kemudian data tersebut dicetak lalu menghasilkan keluaran berupa laporan data pasien untuk diserahkan kepada kepala bidan.

\section{SIMPULAN}

Simpulan yang diperoleh dari pembuatan perancangan aplikasi rekam medis yaitu sistem yang ada pada Bidan Evi menjadi terkomputerisasi, rapih dalam hal penyimpanan data dan laporan, proses pendataan menjadi lebih mudah untuk Perawat dan Bidan Evi. Aplikasi ini menjadikan setiap proses menjadi efektif dan dengan sistem yang terkomputerisasi masalah yang ada dapat dihindari dan meningkatkan cara kerja yang akurat.

\section{DAFTAR PUSTAKA}

Achmadi, A. \& N. (2011). Teori Metodologi Penelitian. Teori Metodologi Penelitian.

Dimas. (2013). INFORMASI), Pengertian SI (SISTEM INFORMASI).

Kasmir (2016: 68). (2019). BAB II Kajian Pustaka 2.1 Pengertian Analisis. FKIP Universitas Jambi.

Mulyani, P. D. S. (2014). Pengertian Erd. Marlinda.

Pamungkas, A. (2020). Rancang Bangun Sistem Informasi Pelayanan Kesehatan Untuk Rekam Medis Rawat Jalan Pada Klinik Pratama Afiyah Medika Berbasis Desktop, 1(2), 56-60.

Rosa AS, m. S. (2014). Pengertian Class Diagram. Rekayasa Perangkat Lunak.

Rosa, \& Shalahuddin, M. (2018). Pengertian Waterfall. Rekayasa perangkat lunak Terstruktur dan Berorientasi Objek.

Soleh, M., Ii, P., \& Joko, I. I. (2014). Pengembangan Sistem Rekam Medis Berbasis Java J2se Di Rsia Bina Sehat Mandiri.

Windu, \& Gata. (2013). Pengertian Usecase. Usecase.

Yanmed, D. B. (2012). Kamus Indikator Kinerja Rumah Sakit dan Balai. 